$\mathrm{Oz}$

$1-1-2009$

\title{
The Matter of Relevance: notes on research, design, and making within practice
}

John Enright

Follow this and additional works at: https://newprairiepress.org/oz

Part of the Architecture Commons

(c) $19 \Theta$

This work is licensed under a Creative Commons Attribution-Noncommercial-No Derivative Works 4.0 License.

\section{Recommended Citation}

Enright, John (2009) "The Matter of Relevance: notes on research, design, and making within practice," Oz: Vol. 31. https://doi.org/10.4148/2378-5853.1463

This Article is brought to you for free and open access by New Prairie Press. It has been accepted for inclusion in Oz by an authorized administrator of New Prairie Press. For more information, please contact cads@k-state.edu. 


\title{
The matter of relevance: notes on research, design, and making within practice
}

\author{
John Enright
}

The spread of the word 'design' doesn't come at a time when there is less to do; it comes at a time when there is more to do. Infinitely more, since it is the whole fabric of life that is now concerned thanks to the ecological crisis. What no revolution has contemplated, namely the remaking of our collective life on earth, is to be carried out with exactly the opposite of revolutionary and modernizing attitudes. This is what renders the spirit of our time so interesting. President Mao was right after all: the revolution has to be always revolutionalized. What he did not anticipate is that the new 'revolutionary' energy would be taken from the set of attitude that are hard to come by in revolutionar movements: modesty, care, precautions, skills, crafts, meanings, attention to details, carefu conservations, redesign, artificiality, and eve shifting transitory fashions. We have to be radically careful, or carefully radical... What an odd time we are living through. ${ }^{1}$

s Bruno Latour has stated, we are Lin an odd time indeed. During the last two decades, architecture has experienced a revolution in new digitally driven modes of how we conceive, design, and implement built form. While this has brought about fundamentally new ways and manners of collaboration between architects, designers, builders, manufacturers and others, it also questions the relevance of traditional models of what architects actually $d o$. It is entirely conceivable that the same advancement of threedimensional software and technology that contemporary architects are so drawn to will inevitably outmode the traditional role of the architect. This is occurring rapidly in the construction industry, as contractors and builders see the obvious advantages of sophisticated software platforms that use information and simulation to aid in the making of built form through associated technologies. Architects are in a panic today, not only from the current economic condition, but because we are witnessing nothing less than the complete marginalization of the traditional field of architecture. The architect's old notions of control and authorship are being called into question as the fundamental way built form is managed and controlled is becoming a much more open and dynamically fluid system. Paralle developments in the pursuit of digitally driven form and manufacturing have pushed the limits of possibilities of the architectural project.

Yet architecture is still a materially driven endeavor, and research into material and its effects within the digital realm of simulation and manufacturing is today where architects can still find territory for relevance. "It is intriguing to note that this emerging, technologically enabled transformation of the building industry in the 'digital' age has led to a much greater integration of 'mechanical' age processes and techniques into conceptual building design."3 This observation is particularly useful given Latour's statement regarding the set of attitudes needed in today's climate, which is to say that it is important that architects continue to explore notions of "making" within the current digitally driven modes of "design." Material research holds the key to this endeavor, for it is through this investigation that new modes of "making" can be developed and nurtured towards future applications.

Within our practice, different projects of multiple scales form threads of trajectories that develop from conceptual research to applied projects. I will focus on three projects that demonstrate this continuity. They happen to be based on environmental issues, but that is not the most important aspect of them, rather they are seen as snap-shots of a larger continuum of material research from the purely non-utilitarian towards a more traditionally applied building commission. Within all three projects however, there is a conscious effort to both investigate digitally driven form within the projects while immersing ourselves in haptic notions of materia and "making." There are two trajectories occurring; one is the development from the conceptual to the applied, and the other is the emergence of the digita towards the material, particularly as they relate to phenomenological and tactile aspects of performative surfaces.

$\mathrm{O}_{t}^{\mathrm{u}}$ Keep Off the Grass: Planar Landscape Phenomena project was an installation at the Southern California Institute of Architecture (SCI-Arc) Gallery. As there was no real program or pedagogical agenda related to the installation, we were able to investigate work in a form that was free from the typical constraints placed on projects. This temporary project acted as a critique on the environmental impact of Southern Californians' devotion to their perfectly manicured lawns. Our challenge was to expose the hidden environmental and societal costs of using sod, a seemingly inexpensive, hybrid material, within the constraints imposed by an extremely lean budget that necessitated the actual construction of the installation by our office Figure 7. This exercise developed into research on the effects of sod on the environment, a material at once organic and manufactured, while simultaneously formally responding to other projects we were investigating regarding conoid and ruled surfaces as they relate to curvature. An earlier project - an addition to an existing Boys' and Girls' Club - had previously developed the notion of a continuous ruled surface that mediated between wall, roof, and topography.

Over 1,000 square feet of hydroponic grass was treated as a surface and formed into an undulating, hovering carpet suspended over the floor of the gallery, nearly filling the space. To underscore the plane as a floating piece, the entire structure was hung from steel cables attached to the gallery ceiling, leaving the space beneath it free. Figures 4-5. Two parallel 12"-deep CNC milled plywood beams provided the primary support for seventy 1 " steel pipes placed a foot apart. The attachment of the pipes to the plywood beams was purposely separated so the plywood appeared to be floating slightly beneath the underside of the sod. In one area the sod was omitted, allowing an unobstructed view of the support system. The undulating form was obviously derived from notions of rolling bucolic hills. The curvilinear plane descended towards the gallery's entrance inviting the viewer into the space, while further deformations arched toward the back of the gallery where a large "subterranean" volume was created by the underside of the 


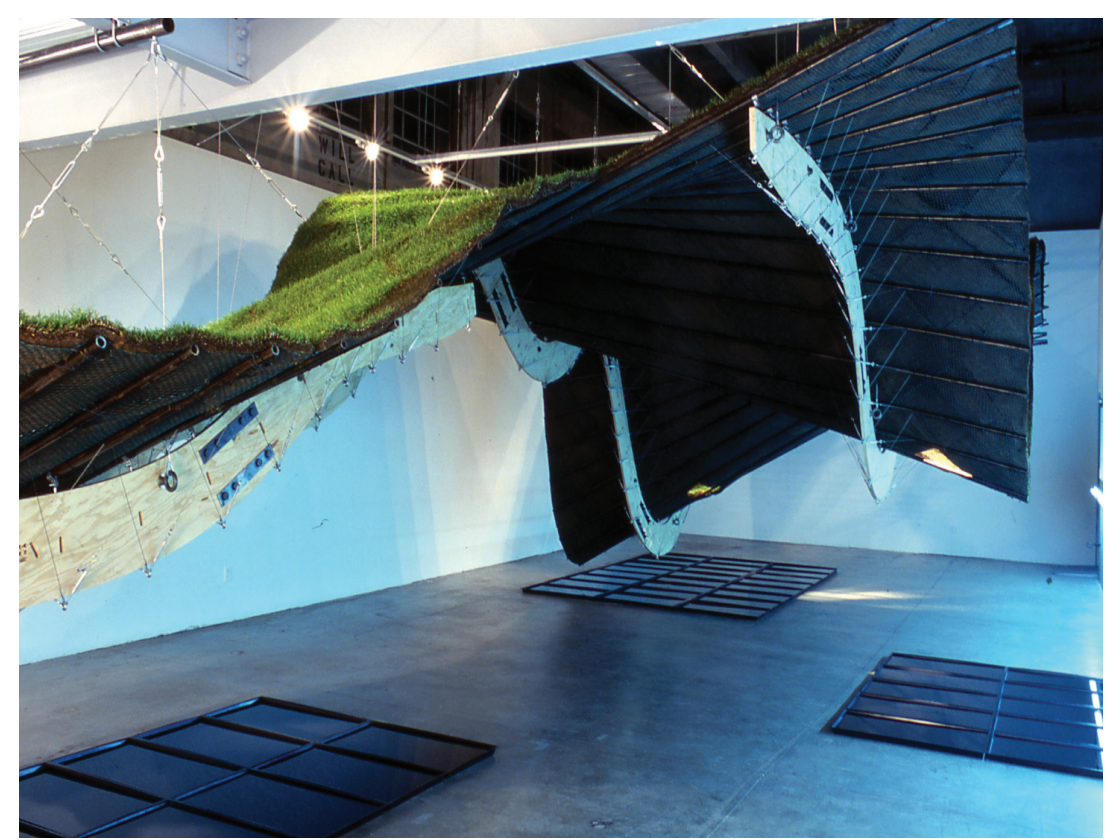

1. Keep Off the Grass: Planar Landscape Phenomena. View from below the installation.
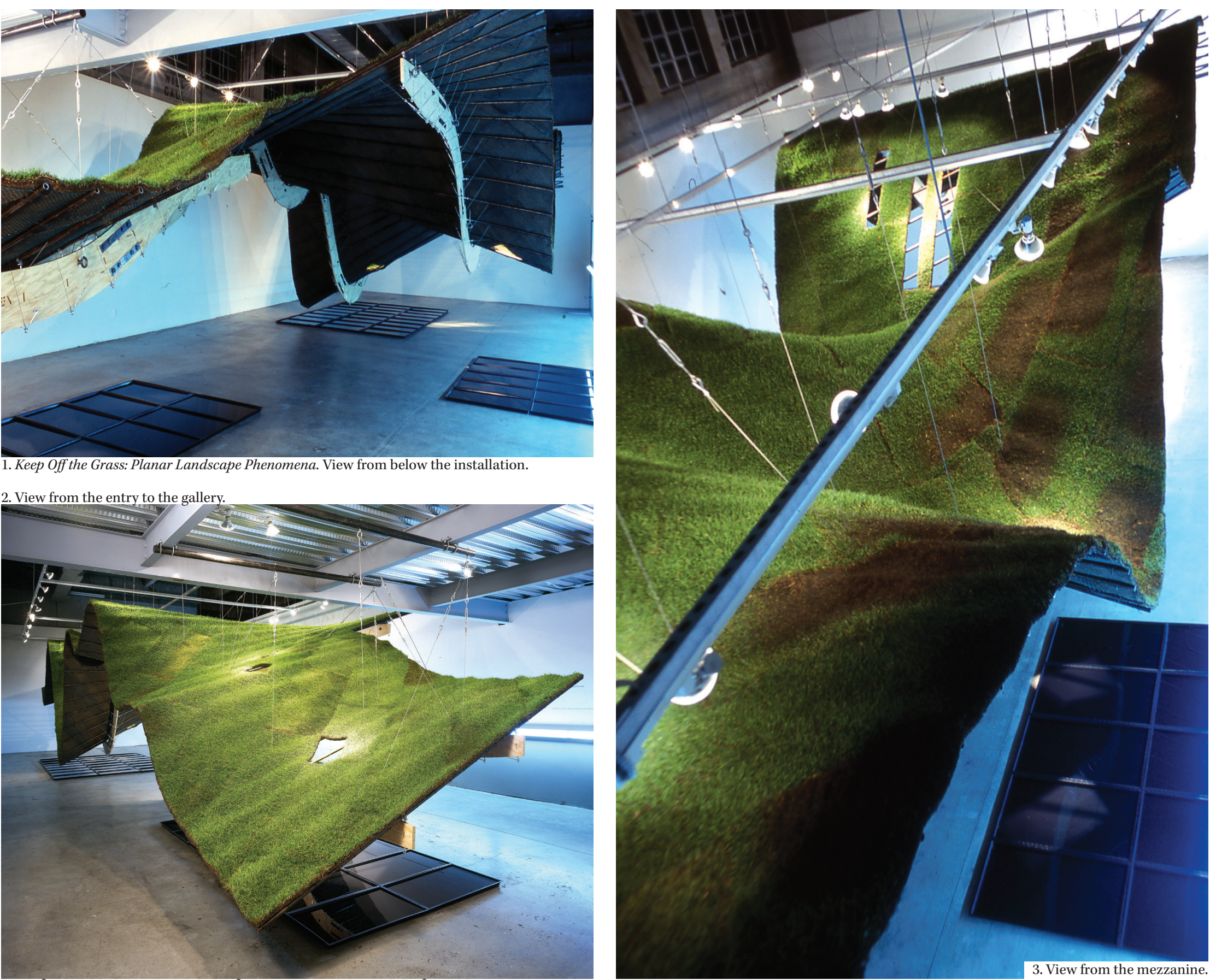
roots and supporting structure. The undulations required the viewer to move around, under, and finally above the form to the gallery balcony to fully read the piece.

We revealed our research through a heuristic exercise, listing sobering statistics on the walls that critiqued the pervasive use of grass in an arid environment Figure 4. A long, horizontal strip of light was placed against the wall $31 / 2$ feet above the floor, as a visual record of the volume of water needed to maintain the sod for one year. Pools of water placed beneath the grass, but beyond its reach, caught and reflected light aimed at perforations in the sod surface Figures 1-3.

The installation was both a digitally designed form and a material investigation that required hands-on solutions to the physical realities of the space, budget and technology available to us. Of particular difficulty was the connection between the inherently two-dimensional CNC plywood beams and the dynamically angled pipe supports. The solution, derived from dynamic structural analysis of the inevitable buckling forces on the beams, involved the use of cable bracing and off-the-shelf tensioning couplers.

The entropic nature of the organic material enabled a transformation of the installation over the course of eight weeks. By deliberately not watering the grass, we triggered a deteriorating process, causing it to slowly decay, dry and shrink Figures 8-9. The scent that resulted could be detected throughout the building, extending well beyond the gallery space. As the material diminished, the porosity increased, altering the quality of light coming through the perforations. The deterioration underscored our precarious relationship to landscape while reminding us of the disproportionate need even a small amount of sod has for water. The project spurred interest for us in how surfaces can perform to a given effect.

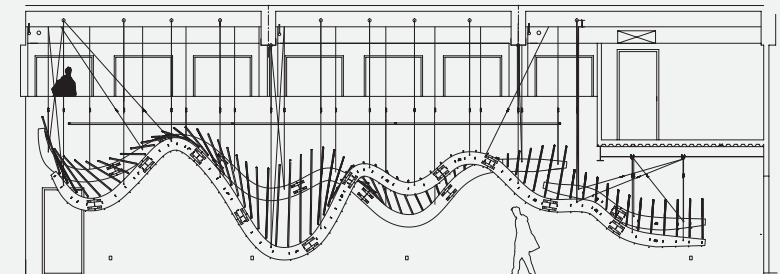

4. Section view.
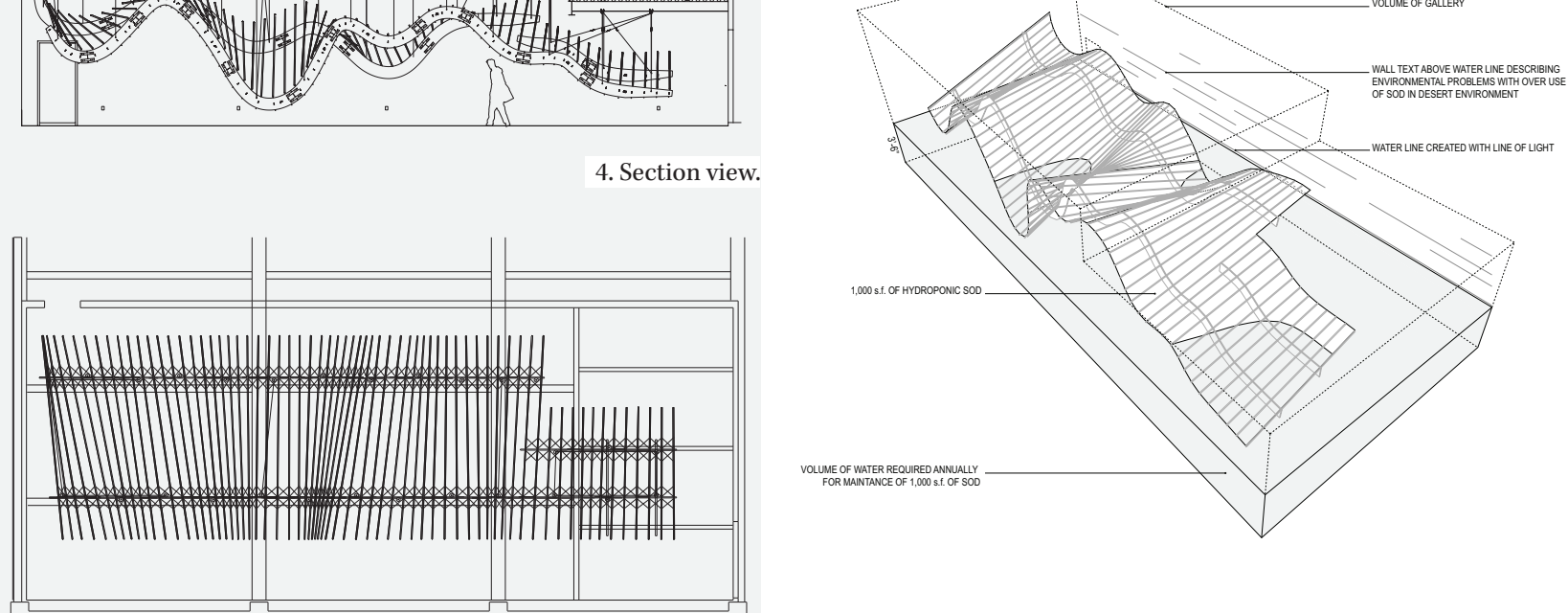

5. Plan view.

6. Installation component diagram

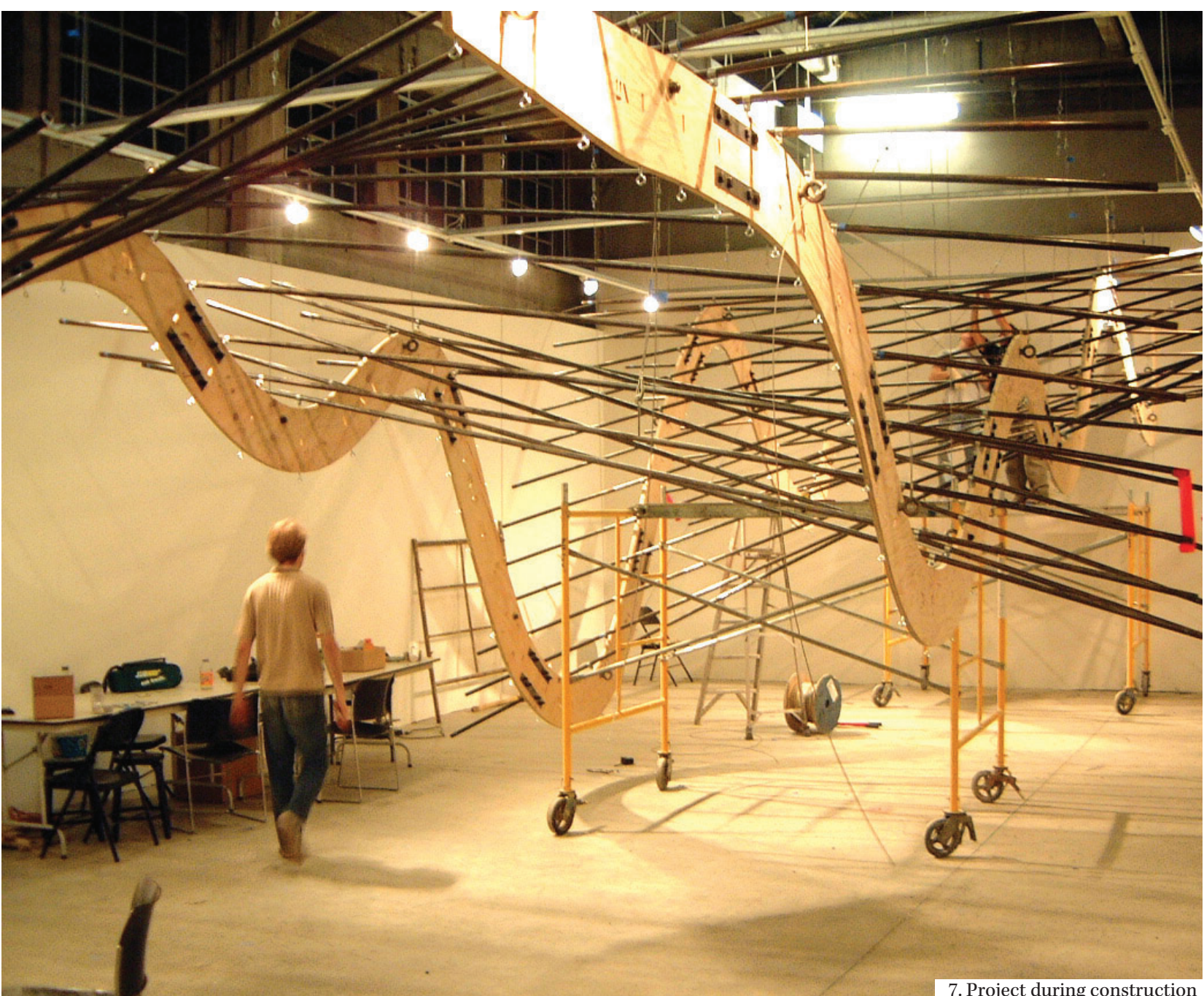



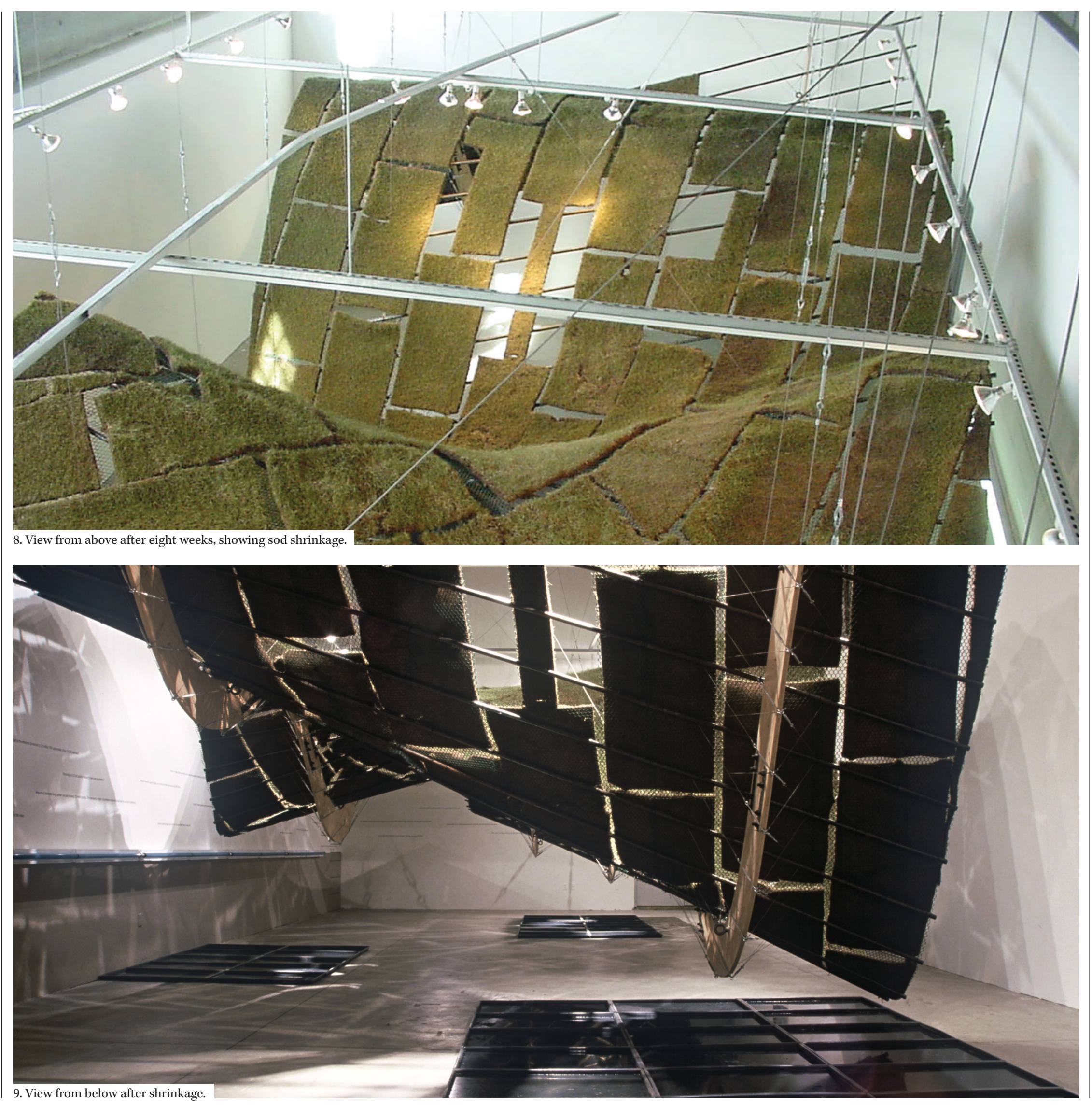
utilitarian and existed within an artistic realm, we began to look at applications of other manufactured environmental material that also contained qualities of thinness and light.

$\Delta$ nother project was a response Ito a competition for a new café for SCI-Arc. This project became an investigation into mobility and material vis-a-vis a specific solar technology that interested us. Research into polyvinyl thin-film photovoltaic material was the basis of the project, especially regarding how it could be manipulated both formally and performatively Figure 10. We were simultaneously interested in pushing the material towards a dynamic formal quality that also performed in an energy generating manner. Studies in the manipulation of curvature related to the panelization and orientation of the material as it was applied to a mobile device fed the formal manifestation of the final proposal Figure 11.

The intent of this project was to create an instrument which simultaneously spoke to SCI-Arc's elongated physical structure (a 1/4mile long former freight building), its associated circulation, kinetic signage, mobility, and sustainable energy technology. SCI-Arc's café became for us, a solar-assisted vehicle that navigated the west façade of the long building, which contained a kitchen, service bar, and counter seating. Some additional space for seating was provided on a porch-like structure Figure 15. The café could be relocated to various positions along the building, simultaneously creating a visible marker for visitors to events at the school. Like a slow moving dirigible, the vehicle signaled a shifting center of gravity within the institute Figures 12-14. It was imagined that the vehicle could be moved at different times of the day, perhaps towards the lecture space in the mornings and at lunch during peak usage. Our design recognized and reinforced the existence of multiple

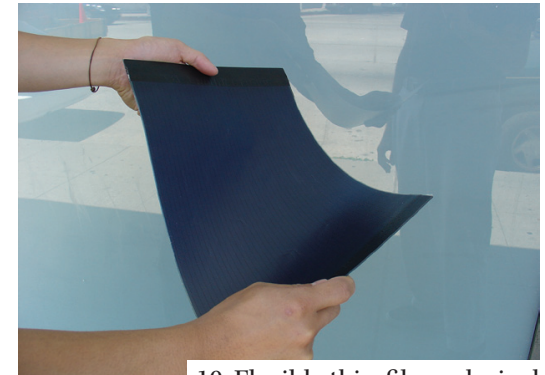

10. Flexible thin-film polyvinyl photovoltaic fabric panel.
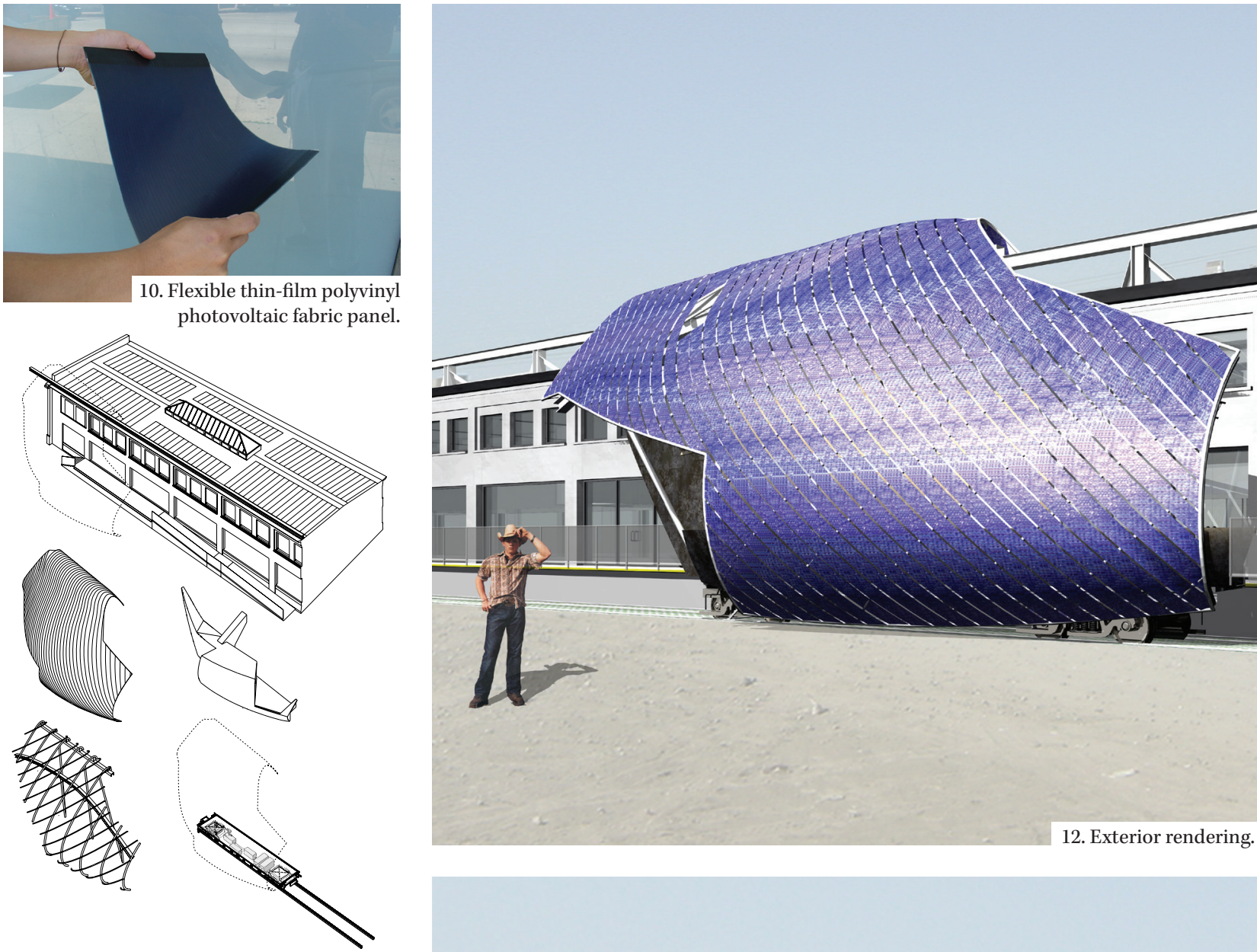

11. SCI-Arc Café. Component diagram.

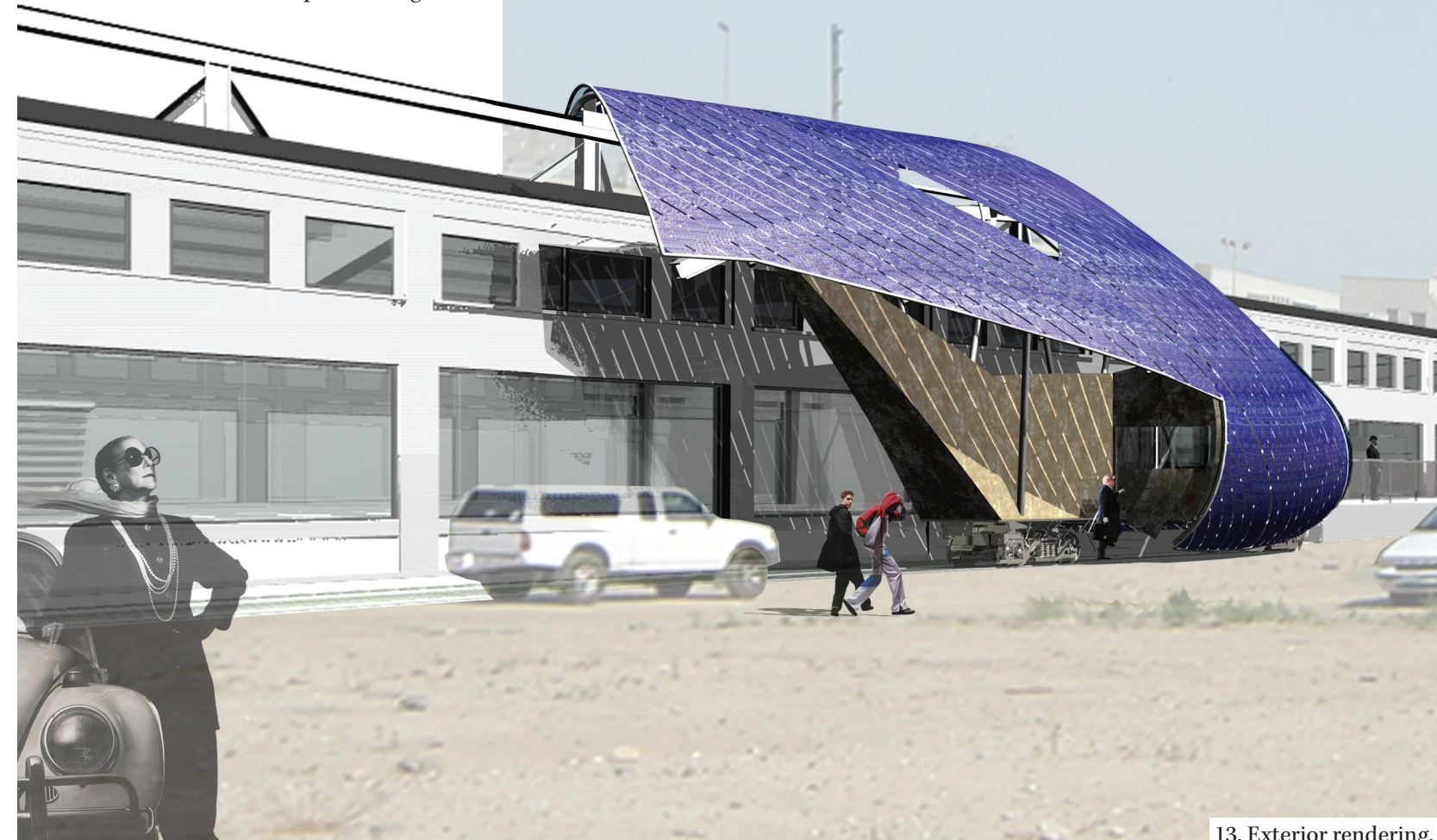




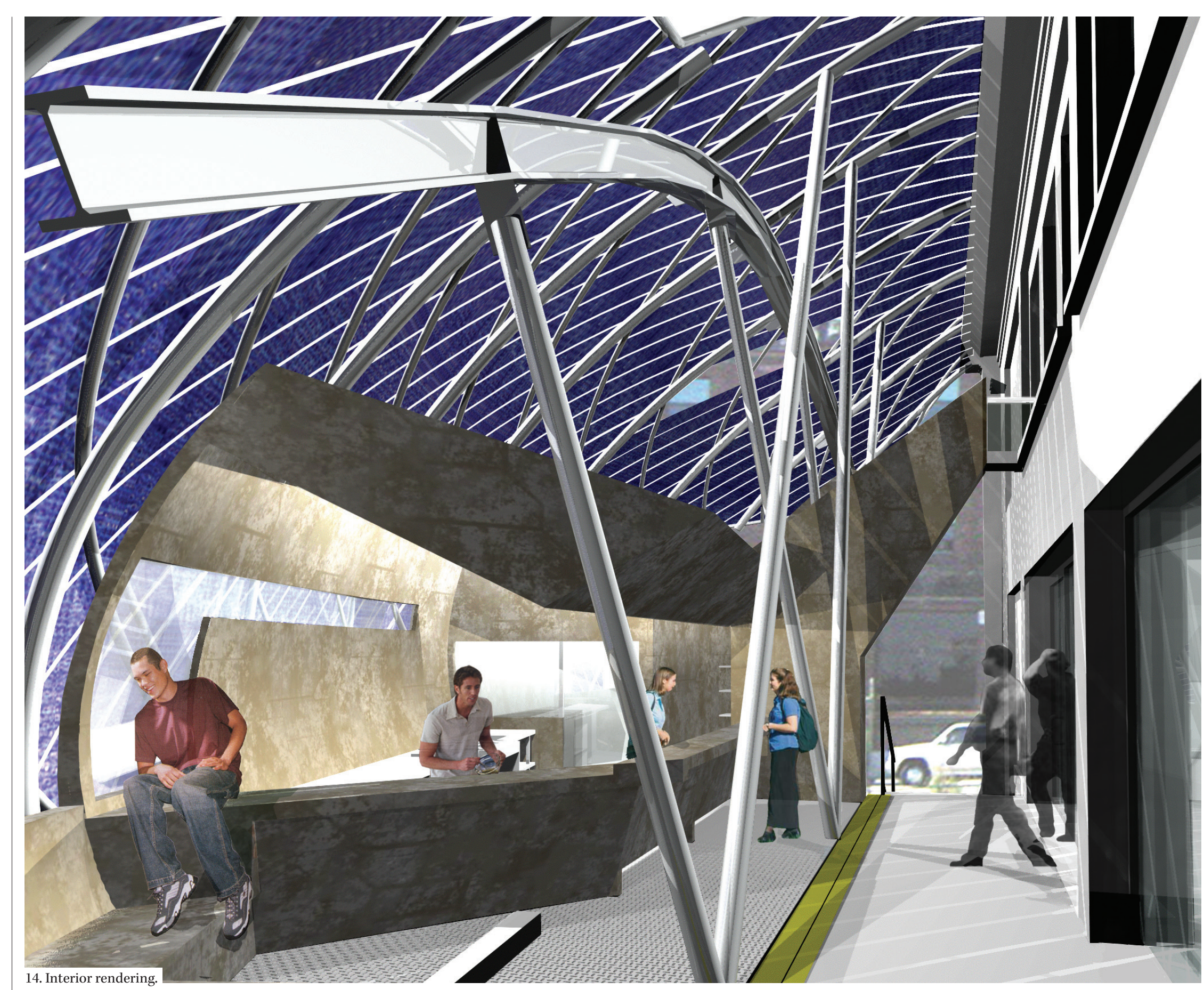

II)

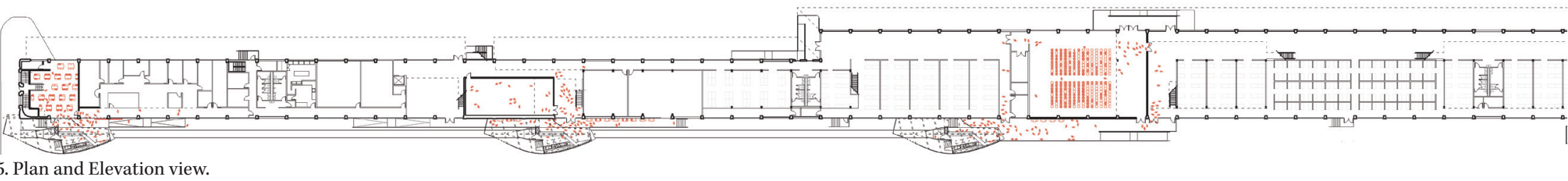


and created an instrument for change that could be manipulated by the faculty and the students.

A commissioned project currently in development can be seen as a continuum and synthesis of both of the previous projects' research. Venice Place Lofts is a mixed-use project containing 16 live/work lofts, commercial, retail, and office space, and underground parking. The elongated narrow site is wrapped with two separate kinds of facades that merge within a series of roof terraces serving the housing units. The southern façade is a series of thin-film polyvinyl photovoltaic fabric panels that create a trellis shade structure over a long walkway connecting the units. This form undulates along the façade, generating electric energy for the project while creating a spatial armature that connects the circulation spine of the project. The deformation of the strip panels creates varying light modulations along the pathway. The northern facade is a series of thick CNCmilled insulated panels that transform to create a family of varying modules. The panels fold over the building mass to facilitate the movement from each lower unit to the roof gardens. Each panel is manipulated to create varying apertures that study ways of bringing natural light into the residential units, creating obtuse windows that capture views and light from divergent angles Figures 16-17. The two major facades meet in an alternating rhythm of photovoltaics and insulated panels, creating a dynamic landscaped roof

18 terrace that holds drought resistant plants. The notion that the surfaces of the project are both materially investigative and formally manipulated is the direct outcome of our previous material research. Here they are applied within a project at an urban scale that both mediates two separate building enclosures and coalesces to form a new hybrid type of roof-scape Our material research has served to inform the performative aspects of the projects materials, yet also continuing to investigate the formally driven, optical variations of each surface.

$\mathrm{W}$

hile digital technologies are opening up new possibilities in formal investigations and fabrication, it is more and more important to us that the tactile, hands-on, and material based research continues to feed our work in ways that the digital cannot. This may be architecture's last stand, as we continue to embrace the new abstractions of digital modes of designing, further and further distancing ourselves from the haptic and tactile. There may yet be hope, if we continue to mediate between the ethereal and the corporal. Certainly, within any contemporary architectural practice dealing within the built environment, the opportunities and avenues of invention of any given project are admittedly varied and sometimes de facto realities in the task at hand. It is in this breadth of the architectural endeavor that one finds territory for exploration. Within each project's specific constraints come invention and opportunity.

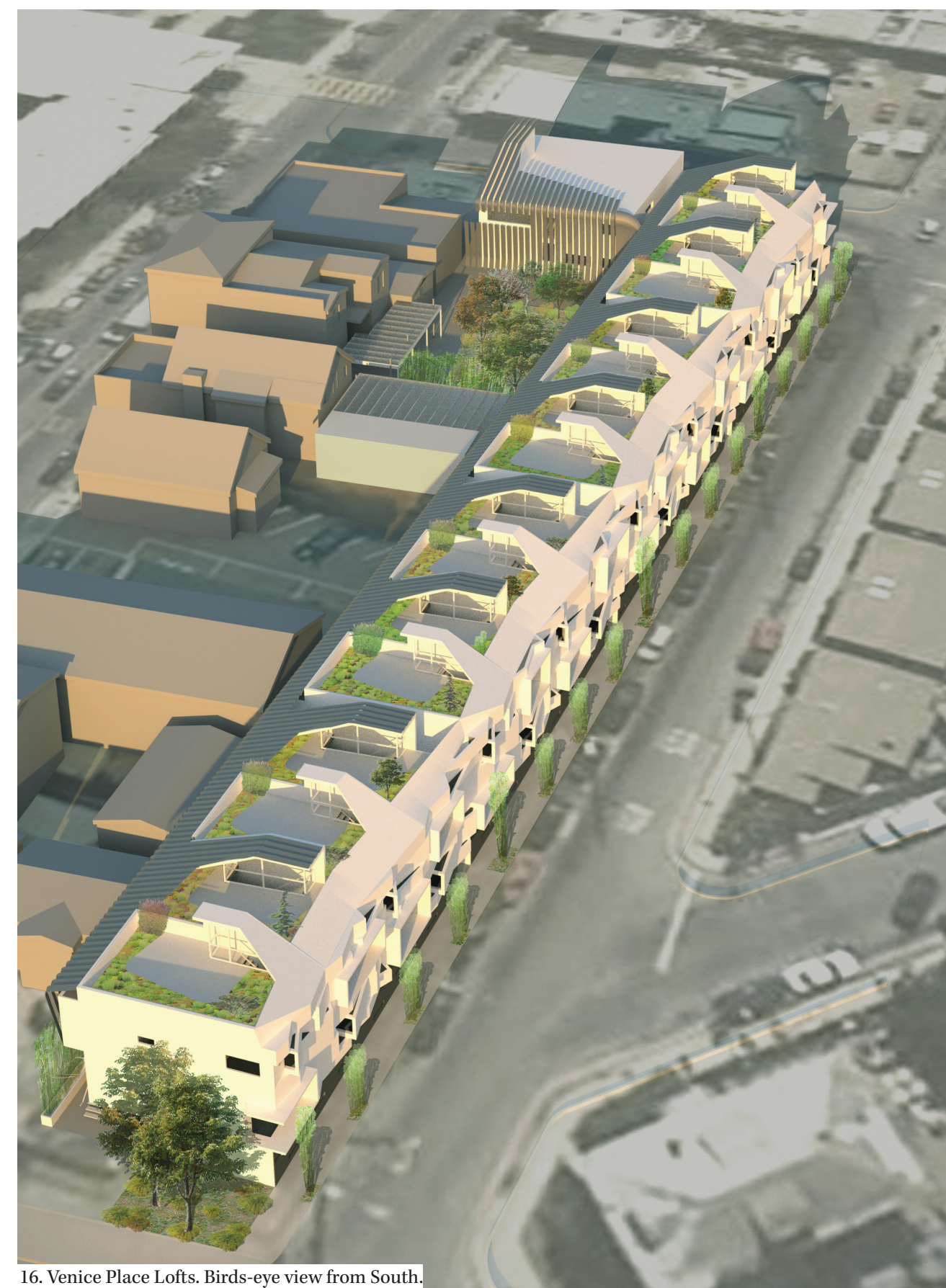




\section{Notes}

${ }^{1}$ Bruno Latour, keynote lecture for the Networks of Design meeting of the Design History Society Falmouth, Cornwall, September 3, 2008.

"Change or perish. You need to prepare yourself for a profession that you are not going to recognize a decade from now." Remarks by Thom Mayne on building information modeling at the 2005 AIA Convention, Las Vegas, NV.

${ }^{3}$ Branko Kolarevic, Ed., Manufacturing Material Effects: Rethinking Design and Making in Architecture, (New York: Routledge, 2008) 7.

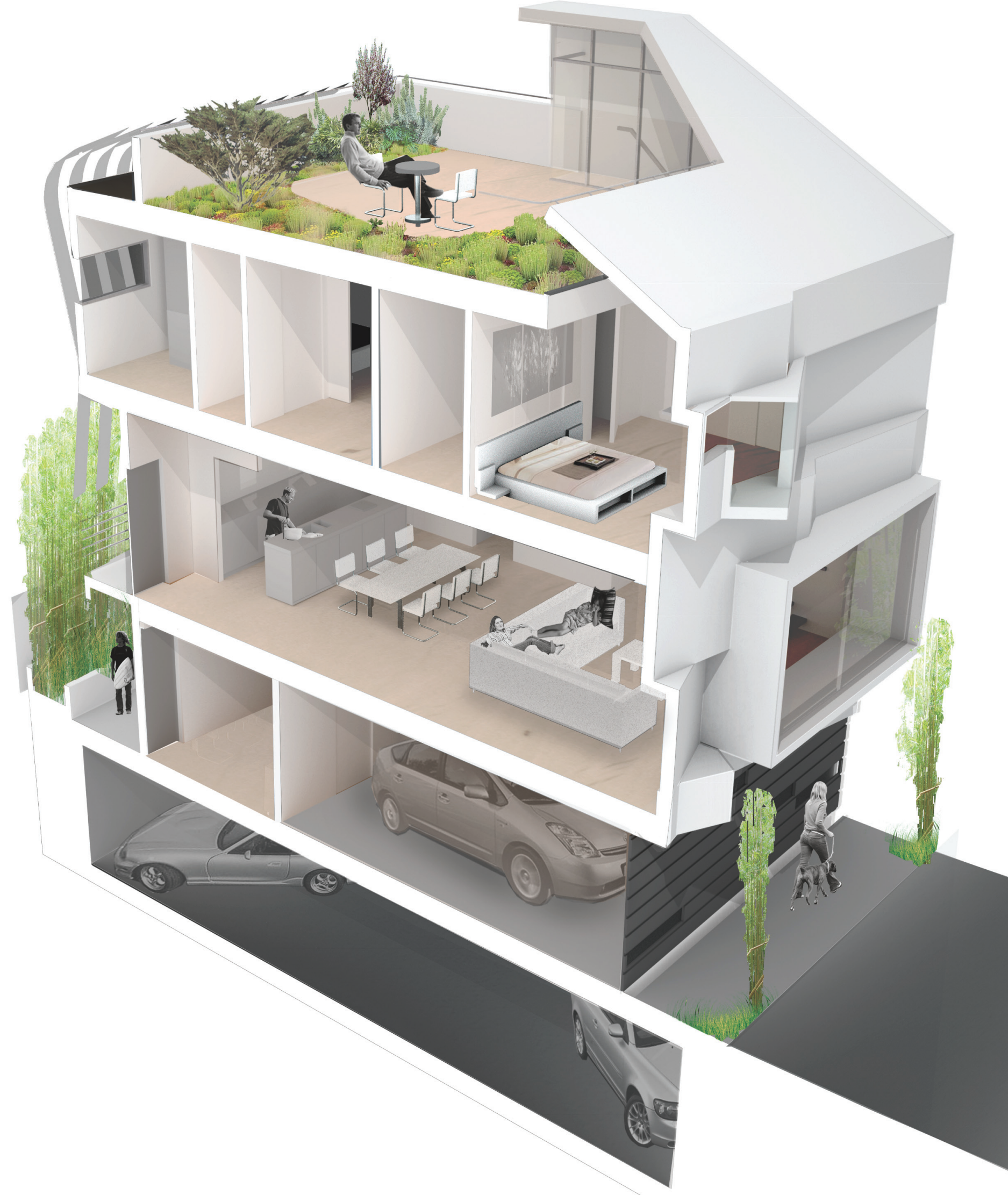

